\title{
The role of a Mediterranean diet on the risk of oral and pharyngeal cancer
}

\author{
M Filomeno ${ }^{1}$, C Bosetti ${ }^{\star}, 2$, W Garavello ${ }^{3}$, F Levi $^{4}$, C Galeone ${ }^{2}$, E Negri ${ }^{2}$ and C La Vecchia ${ }^{1}$ \\ ${ }^{1}$ Department of Clinical Sciences and Community Health, Università degli Studi di Milano, Milan, Italy; ${ }^{2}$ Department of \\ Epidemiology, IRCCS—Istituto di Ricerche Farmacologiche 'Mario Negri', Milan, Italy; ${ }^{3}$ Department of Surgery and Translational \\ Medicine, Clinica Otorinolaringoiatrica, Università degli Studi di Milano Bicocca, Milan, Italy and ${ }^{4}$ Cancer Epidemiology Unit, \\ Institute of Social and Preventive Medicine (IUMSP), Lausanne University Hospital, Lausanne, Switzerland
}

Background: The Mediterranean diet has a beneficial role on various neoplasms, but data are scanty on oral cavity and pharyngeal (OCP) cancer.

Methods: We analysed data from a case-control study carried out between 1997 and 2009 in Italy and Switzerland, including 768 incident, histologically confirmed OCP cancer cases and 2078 hospital controls. Adherence to the Mediterranean diet was measured using the Mediterranean Diet Score (MDS) based on the major characteristics of the Mediterranean diet, and two other scores, the Mediterranean Dietary Pattern Adherence Index (MDP) and the Mediterranean Adequacy Index (MAl).

Results: We estimated the odds ratios (ORs), and the corresponding $95 \%$ confidence intervals (Cl), for increasing levels of the scores (i.e., increasing adherence) using multiple logistic regression models. We found a reduced risk of OCP cancer for increasing levels of the MDS, the ORs for subjects with six or more MDS components compared with two or less being $0.20(95 \% \mathrm{Cl} 0.14-0.28$, $P$-value for trend <0.0001). The ORs for the highest vs the lowest quintile were 0.20 (95\% Cl 0.14-0.28) for the MDP score (score 66.2 or more vs less than 57.9 ), and 0.48 (95\% Cl 0.33-0.69) for the MAl score (score value 2.1 or more vs value less 0.92 ), with significant trends of decreasing risk for both scores. The favourable effect of the Mediterranean diet was apparently stronger in younger subjects, in those with a higher level of education, and in ex-smokers, although it was observed in other strata as well.

Conclusions: Our study provides strong evidence of a beneficial role of the Mediterranean diet on OCP cancer.

The Mediterranean diet is typical of selected area of countries of the Mediterranean basin-including Italy, Southern France, Greece, Spain, and Morocco-and it is characterised by some common features, that is, frequent consumption of varied vegetables and fruit, cereals, fish and seafood, use of olive oil as the main seasoning fat, moderate alcohol consumption, and relatively low consumption of meat and dairy products (Trichopoulou and Lagiou, 1997). The Mediterranean diet has been reported to reduce the risk of cardiovascular disease (Sofi et al, 2010; Dilis et al, 2012; Misirli et al, 2012; Estruch et al, 2013) and overall mortality (Trichopoulou et al, 1995, 2003; Knoops et al, 2004; Mitrou et al, 2007; Sofi et al, 2010), and to have a favourable role on various common cancers as well (Bosetti et al, 2003; Pelucchi et al, 2009; Verberne et al, 2010; Bamia et al, 2013; Couto et al, 2013).
Several epidemiological studies investigated the role of single food items characteristic of the Mediterranean diet on oral cavity and pharyngeal (OCP) cancer risk and reported that high intakes of vegetables, foods containing carotenoids, and fruit in general are protective against this neoplasm (World Cancer Research Fund and American Institute for Cancer Research, 2007; Lucenteforte et al, 2009). To our knowledge, only two studies have considered the overall role of the Mediterranean diet on OCP cancer (Bosetti et al, 2003; Samoli et al, 2010). A previous Italian study (Bosetti et al, 2003), based on a different data set, considered cancers of the upper aerodigestive tract (UADT), that is, oral cavity, pharynx, oesophagus, and larynx, in relation to adherence to the Mediterranean diet using an a priori Mediterranean Diet Score (MDS), and reported an odds ratio (OR) of 0.40 for six or more 
components of the MDS, compared with less than three components. In a case-control study from Greece (Samoli et al, 2010) conducted in the context of the Alcohol-Related Cancers and Genetic Susceptibility in Europe (ARCAGE) study, a closer adherence to the Mediterranean diet-as measured by the MDS score-was associated with a significant decrease risk of UADT $(\mathrm{OR}=0.70$ for a two-unit increase in the MDS score), whereas after mutual adjustment, no individual dietary component was significantly associated with the risk.

With the aim of adding further epidemiological data on the issue, we investigated the association between the Mediterranean diet and the OCP risk, using data from a case-control study conducted in Italy and French-speaking Switzerland. To measure the adherence to the Mediterranean diet, we used three different $a$ priori defined scores proposed in the literature to combine various foods and food groups, and adopted in various other epidemiological studies (Bach et al, 2006).

\section{MATERIALS AND METHODS}

Participants and study design. A case-control study on OCP cancer was conducted between 1997 and 2009 in the greater Milan area, Italy and in the canton of Vaud, Switzerland (Bravi et al, 2013). Cases were 768 patients (593 men and 175 women) under age 80 years (median 58 years, range: 22-79 years) with incident, histologically confirmed squamous cell cancers of the OCP (excluding cancers of the lip, salivary glands, and nasopharynx), admitted to major teaching or general hospitals in the areas under investigation. Controls were 2078 subjects (1368 men and 710 women, median age 59 years, range: 19-79 years) with no previous history of cancer, admitted to the same hospitals as cases for acute, non-neoplastic conditions, unrelated to tobacco smoking, alcohol drinking, or long-term dietary modifications. Among controls, 19\% were admitted for traumas, $21 \%$ for other orthopaedic conditions, $51 \%$ for acute surgical conditions, and $9 \%$ for other miscellaneous conditions. The proportion of refusals of subjects approached for interview was $<5 \%$ in Italy and about $15 \%$ in Switzerland. The study protocols were approved by the ethical committees of the hospitals involved according to the regulations at the time of the each study conduction, and all participants gave informed consent to participate.

Data collection. Trained personnel interviewed both cases and controls during their hospital stay using a structured questionnaire, including information on sociodemographic characteristics, anthropometric measures, and selected lifestyle habits (including tobacco smoking and alcohol drinking). Subjects' dietary habits during the 2 years before cancer diagnosis or hospitalisation (for controls) were assessed through a validated (Decarli et al, 1996) and reproducible (Franceschi et al, 1993) food frequency questionnaire (FFQ). The FFQ included information on weekly consumption of 78 foods and beverages, as well as a range of recipes, that is, the most common ones in the Italian and Swiss diet, grouped into seven sections: (i) bread and cereal dishes (first courses); (ii) meat and other main dishes (second courses); (iii) vegetables (side dishes); (iv) fruit; (v) sweets, desserts and soft drinks; (vi) milk and hot beverages; (vii) alcoholic beverages. Subjects were asked to indicate the average weekly frequency of consumption of each dietary item; occasional intake (lower than once a week, but at least once a month) was coded as 0.5 per week. An Italian food composition database, integrated with other sources, was used to estimate nutrient and total energy intake in this study (Salvini et al, 1998; Gnagnarella et al, 2004).

Dietary scores. We defined an a priori MDS on the basis of nine characteristics of the traditional Mediterranean diet, as suggested by Trichopoulou et al (1995, 2003): high consumption of cereals (including bread and potatoes), fruit, vegetables, legumes, fish, and high monounsaturated/saturated fatty acid (MUFA/SFA) ratio; low consumption of milk (including dairy products) and meat (including meat products); and moderate alcohol intake. For all components, as cutoff point we used the median sex-specific values among controls. For each study subject and each component, a value of one was attributed if the subject was in the component category characteristic of the Mediterranean diet and a value of zero otherwise: thus, for meat/meat products and milk/dairy products a value of 1 was given for low consumption (below the median); for other food items a value of one was given for high consumption (above the median); and for alcohol, a value of one was given for moderate consumption (over 0 and below the median). The MDS score was defined as the sum of the nine individual binary components obtained, and ranged therefore between zero (no adherence) and nine (maximum adherence).

Two additional scores of adherence to the Mediterranean diet were applied: the Mediterranean Dietary Pattern Adherence Index (MDP) (Sanchez-Villegas et al, 2002) and the Mediterranean Adequacy Index (MAI) (Alberti-Fidanza and Fidanza, 2004). The MDP was calculated by summing up the standardised residuals of the regression of cereals, fruit, vegetables, legumes, moderate alcohol, MUFA/SFA ratio on total calories, and subtracting those of milk and meat. The MDP was then expressed as a percentage of adherence using the range of the values in the sample, and assumed values between 0 (low adherence) and 100 (maximum adherence) (Sanchez-Villegas et al, 2002). MAI was calculated by dividing the sum of the intake of selected typical Mediterranean foods (i.e., bread, cereals, fruit, vegetables, legumes, potatoes, fish, red wine, and vegetable oils) as a percentage of total energy by the sum of the intake of non-typical Mediterranean foods (i.e., milk, cheese, meat, eggs, animal fats and margarines, sweet beverages, cakes, pies and cookies, and sugar) again as the percentage of total energy (Alberti-Fidanza and Fidanza, 2004). In our population, this score ranged between 0.29 and 35.36 units. The three different MDSs were positively correlated: the Spearman correlation coefficients were 0.71 between MDS and MDP, 0.56 between MDS and MAI, and 0.71 between MDP and MAI.

Statistical analysis. We estimated the OR, and corresponding 95\% confidence interval (CI), of OCP cancer for categories of the three scores by unconditional multiple logistic regression models (Breslow and Day, 1980), including terms for age (category, quinquennia), sex (category), study center (category, Italy and Switzerland), year of interview (continuous), years of education (category, $<7,7-<12, \geqslant 12$ ), body mass index (BMI, category, $<20, \quad 20-<25, \quad 25-<30, \geqslant 30 \mathrm{~kg} \mathrm{~m}^{-2}$ ), tobacco smoking (category, never, ex-smoker, and current smoker of $<15,15-<25$, or $\geqslant 25$ cigarettes per day), and total energy intake categories (category, quintiles). We also computed continuous ORs, for an increment of one unit for the MDS and MAI and of 10 units for the MDP.

To investigate whether the association with the three dietary scores was homogeneous across strata of selected covariates, we conducted analyses stratified by age, sex, education, BMI, tobacco smoking, and alcohol drinking. Heterogeneity across strata was tested by likelihood ratio tests and resulting $\chi^{2}$-statistics.

\section{RESULTS}

Table 1 shows the distribution of cases and controls according to centre, sex, age, education, smoking status, alcohol consumption, and BMI. Cases and controls had similar distribution by center and education; cases were more frequently male, had a lower BMI, and were more frequently heavily exposed to tobacco smoking and alcohol drinking than controls. 
Table 1. Distribution of 768 cases of oral and pharyngeal cancer and 2078 controls according to sex, age, education, and other selected variables. Italy and Switzerland, 1997-2009

\begin{tabular}{|c|c|c|c|c|}
\hline \multirow[b]{2}{*}{ Characteristic } & \multicolumn{2}{|c|}{ Cases } & \multicolumn{2}{|c|}{ Controls } \\
\hline & $N$ & $\%$ & $N$ & $\%$ \\
\hline \multicolumn{5}{|l|}{ Center } \\
\hline Italy & 348 & 45.3 & 1001 & 48.2 \\
\hline Switzerland & 420 & 54.7 & 1077 & 51.8 \\
\hline \multicolumn{5}{|l|}{ Sex } \\
\hline Men & 593 & 77.2 & 1368 & 65.8 \\
\hline Women & 175 & 22.8 & 710 & 34.2 \\
\hline \multicolumn{5}{|l|}{ Age (years) } \\
\hline$<50$ & 120 & 15.6 & 483 & 23.2 \\
\hline $50-<60$ & 311 & 40.5 & 607 & 29.2 \\
\hline $60-<70$ & 238 & 31.0 & 645 & 31.0 \\
\hline$\geqslant 70$ & 99 & 12.9 & 343 & 16.5 \\
\hline \multicolumn{5}{|l|}{ Education ${ }^{\mathrm{a}}$ (years) } \\
\hline$<7$ & 143 & 18.6 & 379 & 18.3 \\
\hline $7-<12$ & 278 & 36.2 & 641 & 31.0 \\
\hline$\geqslant 12$ & 347 & 45.2 & 1048 & 50.7 \\
\hline \multicolumn{5}{|c|}{ Body mass index $\left(\mathrm{kg} \mathrm{m}^{-2}\right)$} \\
\hline$<20$ & 98 & 12.8 & 107 & 5.2 \\
\hline $20-<25$ & 356 & 46.4 & 780 & 37.5 \\
\hline $25-<30$ & 248 & 32.3 & 944 & 45.4 \\
\hline$\geqslant 30$ & 66 & 8.6 & 247 & 11.9 \\
\hline \multicolumn{5}{|l|}{ Smoking status ${ }^{a}$} \\
\hline Never smoker & 115 & 15.1 & 1031 & 49.7 \\
\hline Ex-smoker & 134 & 17.6 & 478 & 23.0 \\
\hline \multicolumn{5}{|l|}{ Current smoker } \\
\hline$<15$ cigarettes per day & 41 & 5.4 & 211 & 10.2 \\
\hline 15-24 cigarettes per day & 181 & 23.7 & 288 & 13.9 \\
\hline$\geqslant 25$ cigarettes per day & 292 & 38.3 & 67 & 3.2 \\
\hline \multicolumn{5}{|c|}{ Alcohol consumption (drinks per day) } \\
\hline$<2$ & 168 & 21.9 & 1464 & 70.5 \\
\hline $2-<4$ & 165 & 21.5 & 450 & 21.7 \\
\hline $4-<8$ & 205 & 26.7 & 141 & 6.8 \\
\hline$\geqslant 8$ & 230 & 30.0 & 23 & 1.1 \\
\hline
\end{tabular}

Table 2 shows the median weekly consumption of nine food items included in the MDS score among male and female controls, and the corresponding ORs for OCP cancer. A significant reduced risk was observed for high $v s$ low intake of vegetables $(\mathrm{OR}=0.47$; $95 \%$ CI $0.37-0.60)$, fruit $(\mathrm{OR}=0.68 ; 95 \% \mathrm{CI} 0.53-0.87)$, and MUFA/SFA ratio $(\mathrm{OR}=0.66$; $95 \% \mathrm{CI} 0.51-0.84)$, and for moderate $v s$ non- or heavy drinking of alcoholic beverages $(\mathrm{OR}=0.23 ; 95 \%$ CI 0.18-0.29). No significant associations were found for high $v s$ low consumption of cereals and potatoes $(\mathrm{OR}=0.90)$, legumes $(\mathrm{OR}=1.12)$, and fish $(\mathrm{OR}=1.01)$, and for low $v$ s high consumption of meat and meat products $(\mathrm{OR}=0.81)$, and milk and dairy products $(\mathrm{OR}=1.03)$.

The distribution of OCP cancer cases and controls, and the corresponding ORs according to the MDS, the MDP, and the MAI scores are given in Table 3. A reduced trend in risk was found for increasing levels of the MDS, the ORs for six or more
Table 2. Odds ratios (OR) and $95 \%$ corresponding confidence intervals (CI) for oral and pharyngeal cancer among 768 cases and 2078 controls, according to nine items included in the Mediterranean diet score. Italy and Switzerland, 1997-2009

\begin{tabular}{|c|c|c|c|}
\hline \multirow[b]{2}{*}{ Components } & \multicolumn{2}{|c|}{$\begin{array}{c}\text { Median intake }^{a} \\
\text { (portions per week) }\end{array}$} & \multirow[b]{2}{*}{$\mathrm{OR}^{\mathrm{b}}(95 \% \mathrm{Cl})$} \\
\hline & Men & Women & \\
\hline Vegetables & 11.0 & 11.5 & $0.47(0.37-0.60)$ \\
\hline Fruit & 16.8 & 21.5 & $0.68(0.53-0.87)$ \\
\hline Meat and meat products & 7.2 & 5.5 & $0.81(0.64-1.04)$ \\
\hline Legumes & 0.5 & 0.5 & $1.12(0.88-1.43)$ \\
\hline Cereals and potatoes & 20.9 & 19.8 & $0.90(0.68-1.18)$ \\
\hline Milk and dairy products & 7.1 & 10.3 & $1.03(0.81-1.31)$ \\
\hline Fish & 1.7 & 1.5 & $1.01(0.80-1.26)$ \\
\hline Alcoholic beverages & 0.9 & 0.0 & $0.23(0.18-0.29)$ \\
\hline $\begin{array}{l}\text { Monounsaturated/saturated } \\
\text { fat ratio }\end{array}$ & 1.3 & 1.4 & $0.66(0.51-0.84)$ \\
\hline \multicolumn{4}{|c|}{$\begin{array}{l}\text { Estimates for binary contrasts, that is, moderate consumption vs no/high consumption of } \\
\text { alcohol, for low vs high consumption of meat/meat products and milk/dairy products, and } \\
\text { for high vs low consumption of other items. } \\
\text { a Median portion per week among controls. } \\
b_{\text {Estimates from unconditional logistic regression models adjusted for sex, quinquennia of }} \\
\text { age, study center, year of interview, education, tobacco smoking, alcohol drinking, body } \\
\text { mass index, and total energy intake. }\end{array}$} \\
\hline
\end{tabular}

Table 3. Odds ratios (OR) and $95 \%$ confidence intervals (Cl) for oral and pharyngeal cancer among 768 cases and 2078 controls $^{\mathrm{a}}$ according to the Mediterranean Diet Score (MDS), the Mediterranean Dietary Pattern Adherence Index (MDP), and the Mediterranean Adequacy Index (MAI). Italy and Switzerland, 1997-2009

\begin{tabular}{|c|c|c|c|}
\hline & $\begin{array}{l}\text { Cases } \\
N(\%)\end{array}$ & $\begin{array}{c}\text { Controls } \\
N(\%)\end{array}$ & $\mathrm{OR}^{\mathrm{b}}(95 \% \mathrm{Cl})$ \\
\hline \multicolumn{4}{|l|}{ MDS } \\
\hline $\begin{array}{l}0-2 \\
3 \\
4 \\
5 \\
6-9\end{array}$ & $\begin{array}{l}210(27.34) \\
152(19.79) \\
168(21.88) \\
111(14.45) \\
127(16.54)\end{array}$ & $\begin{array}{l}208(10.01) \\
311(14.97) \\
408(19.63) \\
455(21.90) \\
696(33.49)\end{array}$ & $\begin{array}{c}1.00^{c} \\
0.46(0.33-0.65) \\
0.45(0.32-0.63) \\
0.26(0.18-0.38) \\
0.20(0.14-0.28)\end{array}$ \\
\hline$P$-value for trend & & & $\begin{array}{c}<0.0001 \\
0.73(0.68-0.78)^{b, d}\end{array}$ \\
\hline \multicolumn{4}{|l|}{ MDP } \\
\hline $\begin{array}{l}0-57.85 \\
57.86-60.66 \\
60.67-63.15 \\
63.16-66.16 \\
66.17-100\end{array}$ & $\begin{array}{r}328(42.71) \\
138(17.97) \\
101(13.15) \\
93(12.11) \\
108(14.06)\end{array}$ & $\begin{array}{l}242(11.65) \\
431(20.74) \\
468(22.52) \\
475(22.86) \\
462((22.23)\end{array}$ & $\begin{array}{c}1.00^{\mathrm{c}} \\
0.30(0.22-0.41) \\
0.23(0.17-0.32) \\
0.21(0.15-0.30) \\
0.20(0.14-0.28)\end{array}$ \\
\hline$P$-value for trend & & & $\begin{array}{c}<0.0001 \\
0.33(0.26-0.41)^{b, e}\end{array}$ \\
\hline \multicolumn{4}{|l|}{ MAI } \\
\hline $\begin{array}{l}0.29-0.91 \\
0.92-1.21 \\
1.22-1.56 \\
1.57-2.09 \\
2.10-35.36\end{array}$ & $\begin{array}{l}237(30.86) \\
142(18.49) \\
125(16.28) \\
134(17.45) \\
130(16.93)\end{array}$ & $\begin{array}{l}332(15.98) \\
428(20.60) \\
443(21.32) \\
436(20.98) \\
439(21.13)\end{array}$ & $\begin{array}{c}1.00^{c} \\
0.53(0.38-0.72) \\
0.50(0.36-0.69) \\
0.55(0.39-0.78) \\
0.48(0.33-0.69)\end{array}$ \\
\hline$P$-value for trend & & & $\begin{array}{c}0.0005 \\
0.90(0.79-1.03)^{\mathbf{b}, d}\end{array}$ \\
\hline \multicolumn{4}{|c|}{$\begin{array}{l}{ }^{a} \text { The sum does not add up to the total because of some missing values. } \\
\mathbf{b}_{\text {Estimates from logistic regression model adjusted for sex, quinquennia of age, study }} \\
\text { center, year of interview, education, tobacco smoking, body mass index, and total energy } \\
\text { intake. } \\
c_{\text {Reference category. }} \\
{ }^{d} \text { OR for an increase of } 1 \text { unit. } \\
{ }^{e_{O}} \text { OR for an increase of } 10 \text { units. }\end{array}$} \\
\hline
\end{tabular}


Table 4. Odds ratios (OR) and $95 \%$ confidence intervals (CI) of oral and pharyngeal cancer among 768 cases and 2078 controls according to the Mediterranean Diet Score (MDS), the Mediterranean Dietary Pattern Adherence Index (MDP), and the Mediterranean Adequacy Index (MAI) in strata of selected covariates. Italy and Switzerland, 1997-2009

\begin{tabular}{|c|c|c|c|c|}
\hline & \multicolumn{4}{|c|}{ OR $(95 \% \mathrm{Cl})^{\mathrm{a}}$} \\
\hline & Cases/controls & MDS $^{b}$ & $\mathrm{MDP}^{\mathrm{c}}$ & $M A I^{b}$ \\
\hline \multicolumn{5}{|l|}{ Age } \\
\hline$<60$ & $431 / 1090$ & $0.67(0.61-0.73)^{d}$ & $0.25(0.18-0.34)^{d}$ & $0.76(0.62-0.93)^{d}$ \\
\hline$\geqslant 60$ & $337 / 988$ & $0.80(0.73-0.87)$ & $0.43(0.32-0.58)$ & $0.99(0.86-1.12)$ \\
\hline \multicolumn{5}{|l|}{ Sex } \\
\hline Men & $593 / 1368$ & $0.73(0.68-0.79)$ & $0.29(0.23-0.38)$ & $0.94(0.81-1.09)$ \\
\hline Women & 175/710 & $0.72(0.64-0.81)$ & $0.45(0.30-0.67)$ & $0.77(0.59-1.01)$ \\
\hline \multicolumn{5}{|c|}{ Education (years) } \\
\hline$<7$ & $143 / 379$ & $0.85(0.74-0.97)^{d}$ & $0.75(0.49-1.17)^{d}$ & $1.06(0.95-1.18)^{d}$ \\
\hline$\geqslant 7$ & $625 / 1689$ & $0.70(0.65-0.75)$ & $0.25(0.19-0.32)$ & $0.74(0.61-0.88)$ \\
\hline \multicolumn{5}{|c|}{ Tobacco smoking } \\
\hline Never smoker & $115 / 1031$ & $0.87(0.78-0.98)^{d}$ & $0.59(0.39-0.92)^{d}$ & $0.84(0.63-1.10)^{d}$ \\
\hline Current smoker & $514 / 566$ & $0.73(0.65-0.83)$ & $0.42(0.29-0.63)$ & $1.02(0.87-1.19)$ \\
\hline Ex-smoker & $134 / 478$ & $0.64(0.58-0.71)$ & $0.22(0.16-0.30)$ & $0.79(0.65-0.97)$ \\
\hline \multicolumn{5}{|c|}{ Body mass index $\left(\mathrm{kg} \mathrm{m}^{-2}\right)$} \\
\hline$<25$ & $454 / 887$ & $0.70(0.64-0.76)$ & $0.32(0.24-0.43)$ & $0.91(0.76-1.08)$ \\
\hline$\geqslant 25$ & $314 / 1191$ & $0.76(0.700 .84)$ & $0.33(0.25-0.45)$ & $0.89(0.74-1.07)$ \\
\hline \multicolumn{5}{|c|}{$\begin{array}{l}\text { a Estimates from logistic regression model adjusted for sex, quinquennia of age, study center, year of interview, education, tobacco smoking, body mass index, and total energy int } \\
\text { boR for an increase of } 1 \text { unit. }\end{array}$} \\
\hline
\end{tabular}

MDS components compared with two or less being $0.20(95 \%$ CI $0.14-0.28, P$ for trend $P<0.0001)$. Similarly, we observed a significant inverse association for increasing quintiles of the two other scores: the OR for the highest $v s$ the lowest quintile was 0.20 (95\% CI 0.14-0.28) for the MDP score (score value 66.2 or more $v s$ less than 57.9), and 0.48 (95\% CI 0.33-0.69) for the MAI score (score value 2.1 or more $v s$ value less 0.92 ). The continuous OR was $0.73(95 \%$ CI $0.68-0.78)$ for a unit increment of the MDS, 0.33 (95\% CI $0.26-0.41$ ) for an increase of 10 units of the MDP score, and 0.90 (95\% CI 0.79-1.03) for a unit increment of the MAI score.

The association between the three scores and cancer of OCP was also analysed in strata of selected covariates (Table 4). Risk estimates were consistent across strata of sex and BMI; the associations were somewhat stronger in younger subjects (below age 60), in those with a higher level of education, and ex-smokers.

\section{DISCUSSION}

In the present analysis, we found a strong inverse association between OCP cancer risk and adherence to the Mediterranean diet, as measured by various indexes. This finding is in agreement with those of two previous studies, which investigated the role of the Mediterranean diet on OCP neoplasm (Bosetti et al, 2003; Samoli et al, 2010). The favourable effect of the Mediterranean diet was apparently stronger in younger subjects, in those with a higher level of education, and in ex-smokers, although it was observed in other strata as well.

A few other epidemiological studies, which analysed the role of diet on UADT cancers, found consistent beneficial effects of $a$ priori or a posteriori dietary patterns based on fruit and vegetables or nutrients contained in vegetable foods, and a possible unfavourable effect of dietary patterns based on meats and animal products emerged as well (Bravi et al, 2012; Chuang et al, 2012; Helen-Ng et al, 2012; De Stefani et al, 2013). In particular, a recent pooled analysis of 22 case-control studies (Chuang et al, 2012) within the International Head and Neck Cancer Epidemiology (INHANCE) Consortium, using a dietary pattern characterised by high fruit/vegetable and low red meat intake, reported a significant reduced risk of head and neck cancer $(\mathrm{OR}=0.90$ for an unit increment of the score).

With reference to single-specific components of the Mediterranean diet, fruit and vegetables were associated with a reduced risk of OCP cancer in several case-control studies (Boeing et al, 2006; World Cancer Research Fund and American Institute for Cancer Research, 2007; Lucenteforte et al, 2009). The protective role of vegetables and fruit in OCP cancer has been attributed to their content of several micronutrients, including carotenoids, vitamin $\mathrm{C}$ and $\mathrm{E}$, as well as flavonoids, found to be inversely related to OCP cancer (IARC, 2003; Rossi et al, 2007; World Cancer Research Fund and American Institute for Cancer Research, 2007).

In Mediterranean countries, olive oil is largely consumed and is the main source of monounsaturated fats. Olive oil has been shown to have a favourable influence on various neoplasms, including OCP cancer (Pelucchi et al, 2009), possibly on account of its antioxidant properties attributable both to oleic acid itself and to the presence of other nutrients, such as vitamin $\mathrm{E}$ and polyphenols (Owen et al, 2000).

A beneficial effect of fish intake on OCP cancer has been suggested by several studies (Fernandez et al, 1999), but a few other studies provided direct or null associations (World Cancer Research Fund and American Institute for Cancer Research, 2007; Lucenteforte et al, 2009). 
Meat consumption has been related to an increased risk of OCP cancer, although not all studies provided consistent results (Sapkota et al, 2008; Aune et al, 2009; Lucenteforte et al, 2009; Chuang et al, 2012; Steffen et al, 2012). The unfavourable role of meat on cancers of the UADT has been attributed to its fatty-acid composition and the presence of nitrites, $\mathrm{N}$-nitroso compounds, heterocyclic amines, and polycyclic aromatic hydrocarbons (Phillips, 1999; Zheng and Lee, 2009), although the issue remains unsettled.

The evidence on the role of other dietary items including milk, dairy products, cereals, and sugars on OCP cancer is inconsistent, with several studies reporting both direct and inverse relationships (World Cancer Research Fund and American Institute for Cancer Research, 2007; Peters et al, 2008; Sapkota et al, 2008; Lucenteforte et al, 2009).

High alcohol consumption is strongly associated with cancers of the upper digestive and respiratory tract (IARC, 2010), whereas for moderate consumption, particularly of red wine, the risk is limited, if any (Bagnardi et al, 2013).

In addition to the role of any single component considered, the value of this work is to definitely establish and quantify the favourable impact of the Mediterranean diet on OCP cancer, for which scanty epidemiological data are available. This may well explain the relatively lower rates of this neoplasm in the Mediterranean, as compared with central Europe (Bosetti et al, 2013; La Vecchia et al, 2014).

Limitations of our study include possible recall and selection bias (Breslow and Day, 1980). OCP cancer cases may have changed their diet owing to the disease, although we investigated dietary habits 2 years before cancer diagnosis. Dietary habits of hospital controls may not be representative of the general population, although we selected controls among patients with acute conditions not associated with long-term dietary modifications, and we excluded all diagnoses that might have been associated with tobacco smoking and alcohol drinking. Moreover, information from hospital patients has been shown to be satisfactory reproducible (D'Avanzo et al, 1997). The high participation rate among cases and controls is reassuring against a major role of selection bias. Among the strengths of the study, there are its large sample size, the comparable catchment areas of study subjects, the reproducibility and validity of dietary information, and the allowance for a large number of covariates.

Adherence to the Mediterranean diet was measured using different a priori scores proposed in the literature, that is, the MDS (Trichopoulou et al, 1995), the most commonly used index from epidemiological studies, and two additional scores, the MDP (Sanchez-Villegas et al, 2002) and the MAI (Alberti-Fidanza and Fidanza, 2004). These three scores present a few differences: the MDS and the MDP scores, apart from fish, included the same food items; the MAI score on the other end integrated other food items, that is, eggs, sugar, and sweet foods. The three scores, in any case, gave consistent associations, providing a strong evidence of a beneficial role of the Mediterranean diet on OCP cancer.

\section{ACKNOWLEDGEMENTS}

This work was conducted with the contribution of the Italian Foundation for Research on Cancer (FIRC), the Swiss League Against Cancer, and the Swiss Research Against Cancer/OncoSuisse (KFS-700 and OCS-1633). We thank Ivana Garimoldi for editorial assistance. CG was supported by Fondazione Umberto Veronesi.

\section{REFERENCES}

Alberti-Fidanza A, Fidanza F (2004) Mediterranean Adequacy Index of Italian diets. Public Health Nutr 7: 937-941.
Aune D, De Stefani E, Ronco A, Boffetta P, Deneo-Pellegrini H, Acosta G, Mendilaharsu M (2009) Meat consumption and cancer risk: a case-control study in Uruguay. Asian Pac J Cancer Prev 10: 429-436.

Bach A, Serra-Majem L, Carrasco JL, Roman B, Ngo J, Bertomeu I, Obrador B (2006) The use of indexes evaluating the adherence to the Mediterranean diet in epidemiological studies: a review. Public Health Nutr 9: 132-146.

Bagnardi V, Rota M, Botteri E, Tramacere I, Islami F, Fedirko V, Scotti L, Jenab M, Turati F, Pasquali E, Pelucchi C, Bellocco R, Negri E, Corrao G, Rehm J, Boffetta P, La Vecchia C (2013) Light alcohol drinking and cancer: a meta-analysis. Ann Oncol 24: 301-308.

Bamia C, Lagiou P, Buckland G, Grioni S, Agnoli C, Taylor AJ, Dahm CC, Overvad K, Olsen A, Tjonneland A, Cottet V,

Boutron-Ruault MC, Morois S, Grote V, Teucher B, Boeing H, Buijsse B, Trichopoulos D, Adarakis G, Tumino R, Naccarati A, Panico S, Palli D, Bueno-de-Mesquita HB, van Duijnhoven FJ, Peeters PH, Engeset D, Skeie G, Lund E, Sanchez MJ, Barricarte A, Huerta JM, Quiros JR, Dorronsoro M, Ljuslinder I, Palmqvist R, Drake I, Key TJ, Khaw KT, Wareham N, Romieu I, Fedirko V, Jenab M, Romaguera D, Norat T, Trichopoulou A (2013) Mediterranean diet and colorectal cancer risk: results from a European cohort. Eur J Epidemiol 28: 317-328.

Boeing H, Dietrich T, Hoffmann K, Pischon T, Ferrari P, Lahmann PH, Boutron-Ruault MC, Clavel-Chapelon F, Allen N, Key T, Skeie G, Lund E, Olsen A, Tjonneland A, Overvad K, Jensen MK, Rohrmann S, Linseisen J, Trichopoulou A, Bamia C, Psaltopoulou T, Weinehall L, Johansson I, Sanchez MJ, Jakszyn P, Ardanaz E, Amiano P, Chirlaque MD, Quiros JR, Wirfalt E, Berglund G, Peeters PH, van Gils CH, Bueno-de-Mesquita HB, Buchner FL, Berrino F, Palli D, Sacerdote C, Tumino R, Panico S, Bingham S, Khaw KT, Slimani N, Norat T, Jenab M, Riboli E (2006) Intake of fruits and vegetables and risk of cancer of the upper aerodigestive tract: the prospective EPIC-study. Cancer Causes Control 17: 957-969.

Bosetti C, Bertuccio P, Malvezzi M, Levi F, Chatenoud L, Negri E, La Vecchia C (2013) Cancer mortality in Europe, 2005-2009, and an overview of trends since 1980. Ann Oncol 24: 2657-2671.

Bosetti C, Gallus S, Trichopoulou A, Talamini R, Franceschi S, Negri E, La Vecchia C (2003) Influence of the Mediterranean diet on the risk of cancers of the upper aerodigestive tract. Cancer Epidemiol Biomarkers Prev 12: 1091-1094.

Bravi F, Bosetti C, Filomeno M, Levi F, Garavello W, Galimberti S, Negri E, La Vecchia C (2013) Foods, nutrients and the risk of oral and pharyngeal cancer. Br J Cancer 109: 2904-2910.

Bravi F, Edefonti V, Randi G, Ferraroni M, La Vecchia C, Decarli A (2012) Dietary patterns and upper aerodigestive tract cancers: an overview and review. Ann Oncol 23: 3024-3039.

Breslow NE, Day NE (1980) Statistical methods in cancer research. The analysis of case-control studies. IARC Sci Publ No. 32. Vol. I, IARC: Lyon, France.

Chuang SC, Jenab M, Heck JE, Bosetti C, Talamini R, Matsuo K, Castellsague X, Franceschi S, Herrero R, Winn DM, La Vecchia C, Morgenstern H, Zhang ZF, Levi F, Dal Maso L, Kelsey K, McClean MD, Vaughan T, Lazarus P, Muscat J, Ramroth H, Chen C, Schwartz SM, Eluf-Neto J, Hayes RB, Purdue M, Boccia S, Cadoni G, Zaridze D, Koifman S, Curado MP, Ahrens W, Benhamou S, Matos E, Lagiou P, SzeszeniaDabrowska N, Olshan AF, Fernandez L, Menezes A, Agudo A, Daudt AW, Merletti F, Macfarlane GJ, Kjaerheim K, Mates D, Holcatova I, Schantz S, Yu GP, Simonato L, Brenner H, Mueller H, Conway DI, Thomson P, Fabianova E, Znaor A, Rudnai P, Healy CM, Ferro G, Brennan P, Boffetta P, Hashibe M (2012) Diet and the risk of head and neck cancer: a pooled analysis in the INHANCE consortium. Cancer Causes Control 23: 69-88.

Couto E, Sandin S, Lof M, Ursin G, Adami HO, Weiderpass E (2013) Mediterranean dietary pattern and risk of breast cancer. PLoS One 8 : e55374.

D’Avanzo B, La Vecchia C, Katsouyanni K, Negri E, Trichopoulos D (1997) An assessment, and reproducibility of food frequency data provided by hospital controls. Eur J Cancer Prev 6: 288-293.

De Stefani E, Boffetta P, Correa P, Deneo-Pellegrini H, Ronco AL, Acosta G, Mendilaharsu M (2013) Dietary patterns and risk of cancers of the upper aerodigestive tract: a factor analysis in Uruguay. Nutr Cancer 65: 384-389.

Decarli A, Franceschi S, Ferraroni M, Gnagnarella P, Parpinel MT, La Vecchia C, Negri E, Salvini S, Falcini F, Giacosa A (1996) Validation 
of a food-frequency questionnaire to assess dietary intakes in cancer studies in Italy. Results for specific nutrients. Ann Epidemiol 6: 110-118.

Dilis V, Katsoulis M, Lagiou P, Trichopoulos D, Naska A, Trichopoulou A (2012) Mediterranean diet and CHD: the Greek European prospective investigation into cancer and nutrition cohort. Br J Nutr 108: 699-709.

Estruch R, Ros E, Salas-Salvado J, Covas MI, Corella D, Aros F, Gomez-Gracia E, Ruiz-Gutierrez V, Fiol M, Lapetra J, Lamuela-Raventos RM, Serra-Majem L, Pinto X, Basora J, Munoz MA, Sorli JV, Martinez JA, Martinez-Gonzalez MA (2013) Primary prevention of cardiovascular disease with a Mediterranean diet. N Engl J Med 368: 1279-1290.

Fernandez E, Chatenoud L, La Vecchia C, Negri E, Franceschi S (1999) Fish consumption and cancer risk. Am J Clin Nutr 70: 85-90.

Franceschi S, Negri E, Salvini S, Decarli A, Ferraroni M, Filiberti R, Giacosa A, Talamini R, Nanni O, Panarello G, La Vecchia C (1993) Reproducibility of an Italian food frequency questionnaire for cancer studies: results for specific food items. Eur J Cancer 29A: 2298-2305.

Gnagnarella P, Parpinel M, Salvini S, Franceschi S, Palli D, Boyle P (2004) The update of the Italian food composition database. J Food Comp Analysis 17: 509-522.

Helen-Ng LC, Razak IA, Ghani WM, Marhazlinda J, Norain AT, Raja Jallaludin RL, Rahman ZA, Abdullah N, Zain RB (2012) Dietary pattern and oral cancer risk-a factor analysis study. Community Dent Oral Epidemiol 40: 560-566.

IARC (2003) IARC Handbooks of cancer prevention. In Fruit and Vegetables Vol 8. IARC Press: Lyon, France.

IARC (2010) IARC monographs on the evaluation of carcinogenic risks to humans. In Alcohol Consumption and Ethylcarbamate Vol. 96. IARC Press: Lyon, France.

Knoops KT, de Groot LC, Kromhout D, Perrin AE, Moreiras-Varela O, Menotti A, van Staveren WA (2004) Mediterranean diet, lifestyle factors, and 10-year mortality in elderly European men and women: the HALE project. JAMA 292: 1433-1439.

La Vecchia C, Bosetti C, Bertuccio P, Castro C, Pelucchi C, Negri E (2014) Trends in alcohol consumption in Europe and their impact on major alcohol-related cancers. Eur J Cancer Prev 23: 319-322.

Lucenteforte E, Garavello W, Bosetti C, La Vecchia C (2009) Dietary factors and oral and pharyngeal cancer risk. Oral Oncol 45: 461-467.

Misirli G, Benetou V, Lagiou P, Bamia C, Trichopoulos D, Trichopoulou A (2012) Relation of the traditional Mediterranean diet to cerebrovascular disease in a Mediterranean population. Am J Epidemiol 176: 1185-1192.

Mitrou PN, Kipnis V, Thiebaut AC, Reedy J, Subar AF, Wirfalt E, Flood A, Mouw T, Hollenbeck AR, Leitzmann MF, Schatzkin A (2007)

Mediterranean dietary pattern and prediction of all-cause mortality in a US population: results from the NIH-AARP Diet and Health Study. Arch Intern Med 167: 2461-2468.

Owen RW, Giacosa A, Hull WE, Haubner R, Spiegelhalder B, Bartsch H (2000) The antioxidant/anticancer potential of phenolic compounds isolated from olive oil. Eur J Cancer 36: 1235-1247.

Pelucchi C, Bosetti C, Rossi M, Negri E, La Vecchia C (2009) Selected aspects of Mediterranean diet and cancer risk. Nutr Cancer 61: 756-766.

Peters ES, Luckett BG, Applebaum KM, Marsit CJ, McClean MD, Kelsey KT (2008) Dairy products, leanness, and head and neck squamous cell carcinoma. Head Neck 30: 1193-1205.

Phillips DH (1999) Polycyclic aromatic hydrocarbons in the diet. Mutat Res 443: 139-147.

Rossi M, Garavello W, Talamini R, Negri E, Bosetti C, Dal Maso L, Lagiou P, Tavani A, Polesel J, Barzan L, Ramazzotti V, Franceschi S, La Vecchia C
(2007) Flavonoids and the risk of oral and pharyngeal cancer: a case-control study from Italy. Cancer Epidemiol Biomarkers Prev 16: $1621-1625$.

Salvini S, Parpinel M, Gnagnarella P, Maisonneuve P, Turrini A (1998) Banca di Composizione Degli Alimenti Per Studi Epidemiologici in Italia. Istituto Europeo di Oncologia: Milano, Italia.

Samoli E, Lagiou A, Nikolopoulos E, Lagogiannis G, Barbouni A, Lefantzis D, Trichopoulos D, Brennan P, Lagiou P (2010) Mediterranean diet and upper aerodigestive tract cancer: the Greek segment of the Alcohol-Related Cancers and Genetic Susceptibility in Europe study. Br J Nutr 104: 1369-1374.

Sanchez-Villegas A, Martinez JA, De Irala J, Martinez-Gonzalez MA (2002) Determinants of the adherence to an 'a priori' defined Mediterranean dietary pattern. Eur J Nutr 41: 249-257.

Sapkota A, Hsu CC, Zaridze D, Shangina O, Szeszenia-Dabrowska N, Mates D, Fabianova E, Rudnai P, Janout V, Holcatova I, Brennan P, Boffetta P, Hashibe M (2008) Dietary risk factors for squamous cell carcinoma of the upper aerodigestive tract in central and eastern Europe. Cancer Causes Control 19: 1161-1170.

Sofi F, Abbate R, Gensini GF, Casini A (2010) Accruing evidence on benefits of adherence to the Mediterranean diet on health: an updated systematic review and meta-analysis. Am J Clin Nutr 92: 1189-1196.

Steffen A, Bergmann MM, Sanchez MJ, Chirlaque MD, Jakszyn P, Amiano P, Quiros JR, Barricarte Gurrea A, Ferrari P, Romieu I, Fedirko V, Bueno-de-Mesquita HB, Siersema PD, Peeters PH, Khaw KT, Wareham N, Allen NE, Crowe FL, Skeie G, Hallmanns G, Johansson I, Borgquist S, Ericson U, Egeberg R, Tjonneland A, Overvad K, Grote V, Li K, Trichopoulou A, Oikonomidou D, Pantzalis M, Tumino R, Panico S, Palli D, Krogh V, Naccarati A, Mouw T, Vergnaud AC, Norat T, Boeing H (2012) Meat and heme iron intake and risk of squamous cell carcinoma of the upper aero-digestive tract in the European prospective investigation into cancer and nutrition (EPIC). Cancer Epidemiol Biomarkers Prev 21: 2138-2148.

Trichopoulou A, Costacou T, Bamia C, Trichopoulos D (2003) Adherence to a Mediterranean diet and survival in a Greek population. N Engl J Med 348: 2599-2608.

Trichopoulou A, Kouris-Blazos A, Wahlqvist ML, Gnardellis C, Lagiou P, Polychronopoulos E, Vassilakou T, Lipworth L, Trichopoulos D (1995) Diet and overall survival in elderly people. BMJ 311: 1457-1460.

Trichopoulou A, Lagiou P (1997) Healthy traditional Mediterranean diet: an expression of culture, history, and lifestyle. Nutr Rev 55: 383-389.

Verberne L, Bach-Faig A, Buckland G, Serra-Majem L (2010) Association between the Mediterranean diet and cancer risk: a review of observational studies. Nutr Cancer 62: 860-870.

World Cancer Research Fund and American Institute for Cancer Research (2007) Food, Nutrition, Physical Activity and the Prevention of Cancer: a Global Perspective. American Institute for Cancer Research: Washington DC.

Zheng W, Lee SA (2009) Well-done meat intake, heterocyclic amine exposure, and cancer risk. Nutr Cancer 61: 437-446.

This work is published under the standard license to publish agreement. After 12 months the work will become freely available and the license terms will switch to a Creative Commons AttributionNonCommercial-Share Alike 3.0 Unported License. 